\title{
Selected Bibliography on Byelorussia 1975
}

The present bibliography follows the patterns of those in previous issues of $J B S$. It consists of a selection of new material received by the Francis Skaryna Library before May 1976. Unless otherwise stated, the place of publication is Minsk, and the year 1975.

\section{BOOKS}

\section{Abbreviations of the names of Byelorussian publishing houses}

'B' - 'Biełaruś.

'BDU' - Vydaviectva Biełaruskaha Dziaržaŭnaha Univiersiteta.

'DB' - Dziaržaŭnaja Biblijateka BSSR imia U. I. Lenina.

'ML' - 'Mastackaja litaratura'.

'NA' - 'Narodnaja aśvieta'.

'NT' - 'Navuka i technika'.

'VS' - 'Vyšejšaja škoła'.

\section{Bibliography. Librarianship. History of Printing}

1. Bielaruski knižny znak. Comp. by A. Tyčyna, V. Smataŭ. 'B'. 128 pp. Ill.

2. Carankoŭ, L. Francysk Skaryna i jaho čas. 'BDU'. 64 pp.

3. Ich imionami nazvany vulicy stalicy. Rekamiendacyjny śpis litaratury. Comp. by M. Sokal. 'DB'. 20 pp. (Supplement to Novyja knihi BSSR, 4.)

4. Ista vajna narodnaja. Rekamiendacyjny pakazalnik litaratury. Comp. by A. Leŭ, A. Muraviejka. 'DB'. 68 pp.

5. Kałubovič, A. Mova $\bar{u}$ historyi biełaruskaha piśmienstva. Uvodziny: los pomnikaŭ staroha biełaruskaha piśmienstva (rukapisnaha i drukavanaha). München-London, 1974-75. 85 pp.

6. Katalog belorusskich izdanij kirillovskogo srifta XVI-XVII vv. Vyp. 2 (1601-1654 gg.). Comp. by V. Luk'janenko. The Saltykov-Sčedrin Library, Leningrad. 267 pp.

7. $K$ istorii bibliotečnogo dela $v$ Belorussii. Sbornik naučnych rabot. Ed. by L. Stankevič. 'DB'. 102 pp.

8. Litaratura i mastactva BSSR. 1973. Rekamiendacyjny pakazalnik litaratury. Comp. by M. Kavalenka, K. Prenc. 'DB'. 132 pp.

9. Nauka i naučno-issledovatel'skaja rabota $v$ BSSR. Ukazatel' literatury za 1974 god. Comp. by N. Vitaleva. Fundamientalna biblijateka imia J. Kołasa AN BSSR. 225 pp.

10. Nauka $i$ naučno-issledovatel'skaja rabota $v$ Belorussii (1918-1973 gg.). Tom 1 : Razvitije nauki. Istorija, sostojanije i zadači otdel'nych otraslej. Comp. by A. Vasilevskaja, N. Vitaleva. Fundamentalnaja biblijateka imia J. Kołasa AN BSSR. $324 \mathrm{pp}$.

11. Padpolnyja pieryjadyčnyja vydańni na Bielarusi $\breve{u}$ hady Vialikaj ajčynnaj vajny. Comp. by V. Adamovic. 'DB'. 128 pp.

12. Pamjat' serdca. Velikaja otečestvennaja vojna v belorusskoj muzyke. Rekomendatel'nyj spisok literatury. 'DB'. $16 \mathrm{pp}$. (Supplement to Novyja knihi BSSR, 1.)

13. Piśmieńniki-jubilary. Mietadyčnyja i biblijahrafičnyja materyjały. Comp. by I. Smykava, E. Kraŭcevič. 'DB'. $24 \mathrm{pp}$. (Supplement to Novyja knihi BSSR, 2.) Bibliographical materials on Piatruś Broŭka, Piatro Hlebka and Kuźma Corny.

14. Rukovoditeljam muzykal'nych kollektivov. Bibliografičeskij ukazatel'. Comp. by V. Dyšinevič. 'DB'. 244 pp.

15. Starejšyna biełaruskaj litaratury. Mietadyčnyja i biblijahrafičnyja materyjały da 80-hodździa $z$ dnia naradžeńnia Kandrata Krapivy. Comp. by I. Smykava. 'DB'. 8 pp. (Supplement to Novyja knihi BSSR, 12.) 


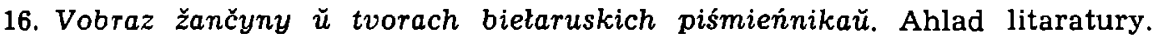
Comp. by M. Kavalenka. 'DB'. 8 pp. (Supplement to Novyja knihi BSSR, 6.)

17. Ženščiny Sovetskoj Belorussii. Rekomendacionnyj spisok literatury. Comp. by I. Smykova. 'DB'. $16 \mathrm{pp}$. (Supplement to Novyja knihi BSSR, 5.)

\section{Dictionaries. Reference}

18. Bardovič, A., Sakun, L. Marfiemny stoŭnik biełaruskaj movy. 'VŠ'. 784 pp.

19. Bielaruskaja Savieckaja Encyklapiedyja. Ed. by P. Broŭka et al. Akademija Navuk BSSR. Hałoŭnaja redakcyja Bieł. Sav. Encykł. Ill. Maps.

Tom 8: Paddubki - Rabki. 676 pp.

Tom 12: Biełaruskaja Savieckaja Sacyjalistyčnaja Respublika, 736 pp.

20. Grabčikov, S. Belorussko-russkij slovar'. 2nd ed. 'NA'. $240 \mathrm{pp}$.

21. Narodnoje chozjajstvo Belorusskoj SSR. Statističeskij ježegodnik. 'B'. $336 \mathrm{pp}$.

\section{Education}

22. Abramenko, M. Nizšaja profesional'naja škola $v$ dorevoljucionnoj Belorussii. 'VŚ'. $64 \mathrm{pp}$.

23. Bespamjatnych, N. Matematičeskoje obrazovanije $v$ Belorussii. Istoričeskij očerk. 'VS''. $288 \mathrm{pp}$.

24. Geografija $v$ èkolach i vuzach Belorussii. Ed. by V. Dement'jev et al. 'VŠ'. $176 \mathrm{pp}$.

25. Gromyko, V. Osobennosti izučenija russkogo jazyka v Belorussii. 'VS'. 128 pp.

26. Kaźbiaruk, U. Jakub Kolas $u$ škole. 2nd ed. 'NA'. 176 pp.

27. Padhajski, L. Bietaruskaja mova $\breve{u}$ trecim klasie. 'NA'. $128 \mathrm{pp}$.

28. Padhajski, L. Vyvučennie bielaruskaj movy $\breve{u}$ pačatkovych kłasach. Hramatyka, pravapis, raźvićcio movy. 'NA'. $256 \mathrm{pp}$.

29. Spravočnik dlja postupajuščich $v$ Belorusskij gosudarstvennyj universitet im. V. I. Lenina. 'BDU'. $128 \mathrm{pp}$.

30. Spravođnik dlja postupajuščch $v$ srednije special'nyje učebnyje zavedenija BSSR v 1975 godu. 'VS'. 104 pp.

31. Spravočnik dlja postupajuščich $v$ vysšije učebnyje zavedenija BSSR $v$ 1975 g. 'VS'. 104 pp.

32. Tamašova. L. Vyvučeńnie paemy Jakuba Kołasa 'Novaja ziamla' ŭ škole. 2nd ed. 'NA'. 1974. $96 \mathrm{pp}$.

33. Universitety trudjaščichsja. Comp. by A. Samal', L. Grickevič. 'B'. 112 pp.

\section{Ethnography. Folklore}

34. Bartaševič, H. Vieršavanyja žanry biełaruskaha dziciačaha falkłoru. 'NT'. $168 \mathrm{pp}$.

35. Bietaruskaja narodnaja tvorčaśc. Byelorussian Folk Art. Comp. and annot. by F. and R. Bartaševič. ' $B$ '. 48 pp. Ill. Text in Byelorussian and English.

36. Biełaruskaje narodnaje adzieńnie. Ed. by V. Bandarčyk. 'NT'. 96 pp. Ill.

37. Cvirka, K. Stova pra Syrakomlu. Byt i kultura biełarusaŭ u tvorčaści 'Viaskovaha lirnika'. 'NT'. $200 \mathrm{pp}$.

38. Hilevič, N. Paetyka biełaruskaj narodnaj liryki. 'VŠ'. 288 pp.

39. Izmenenija $v$ bytu i kul'ture gorodskogo naselenija Belorussii. Ed. by V. Bandarčyk. 'NT'. 111 pp.

40. Min'ko, L. Sujeverija i primety. 'NT'. $192 \mathrm{pp}$.

41. Zimovyja pieśni. Ed .by V. Bandarčyk et al. Comp., introd. and annot. by A. Hurski, mus. ed. Z. Mažejka. 'NT'. 736 pp. Mus. notes. (Part of the series Bietaruskaja narodnaja tvorčaść.)

\section{Geography. Demography. Economics}

42. Balandin, R. Soligorsk i naša planeta. 'VŠ'. 192 pp. Ill.

43. Chodosovskij. V. Svojej sud'by chozjajki. Ženščiny Sovetskoj Belorussii: cifry, fakty, razmyšlenija. 'Hołas radzimy'. 72 pp.

44. Industrializacija Belorusskoj SSR (1926-1941 gg.). Sbornik dokumentov i materialov. Ed. by V. Zigalov et al. ' $B$ '. 468 pp.

45. Jasinskij, O., Gasenkov, V. Mstislavl'. Istoriko-ekonomičeskij očerk. 'B'. 112 pp. Ill. 
46. Kozlovskaja, L. Territorial'naja koncentracija promyšlennosti. 'NT'. 160 pp.

47. Kucharev, N. Žlobin. Istoriko-ekonomičeskij očerk. 'B'. 112 pp. Ill.

48. Monič Z. et al. Rabočij klass $v$ strukture sel'skogo naselenija. 'NT'. 200 pp.

*** Narodnoje chozjajstvo Belorussii. See no. 21.

49. Raševskij, N. Brestskaja oblast'. 2nd ed. 'B'. 252 pp. Ill.

51. Sachot'ko, L. Roždajemost' v Belorussii. (Social'no-ekonomičeskije voprosy). 'NT'. $168 \mathrm{pp}$.

\section{History}

52. Aleksandrovič, S. Volnadumca z-pad Niaśviža Alaksandr Niezabytkoŭski. Z historyi biełaruska-polskich litaraturnych i hramadska-palityčnych suviaziej u 40-ja hady XIX stahodździa. 'BDU'. 120 pp.

53. Doktaraŭ, U. Pad hatyčnymi sklapieńniami kaściolaŭ. Palityka katalicyzmu ŭ BSSR. 'B'. 72 pp.

54. Drevnerusskije knjažestva X-XIII vv. Ed. by L. Beskrovnyj et al. 'Nauka', Moscow. 304 pp.

Aleksejev, L. 'Polockaja zemlja' (202-39); Sedov, V. 'Smolenskaja zemlja' (240-59).

55. Grickevič, A. Castnovladel'českije goroda Belorussii v XVI-XVII vv. 'NT'. $248 \mathrm{pp}$.

56. Historyja Bielaruskaj SSR. U piaci tamach. Gen eds. I. Ihnacienka, L. Abecedarski et. al. Ill. Maps.

Tom 4: Biełaruś napiaredadni i ŭ hady Vialikaj ajčynnaj vajny Savieckaha Sajuza (1938-1945 hh.). $640 \mathrm{pp}$.

Tom 5: Biełaruskaja SSR u pieryjad stvareńnia raźvitoha sacyjalistyčnaha hramadstva i budaŭnictva kamunizmu (1945-1974 hh.). 776 pp.

*** Išla vajna narodnaja. See no. 4.

57. Kopysskij, Z. Social'no-političeskoje razvitije gorodov Belorussii $v$ XVI pervoj polovine XVII v. 'NT'. 192 pp.

58. Krutalevič, V. Roždenije Belorusskoj Sovetskoj Respubliki. 'NT'. 336 pp.

59. Kucharev, B. Sel'skoje chozjajstvo Zapadnoj Belorussii (1919-1939 gg.). 'VS'.

60. Lipinskij, L. Krest'janskoje dviženije v Belorussii v 1914-1917 gg. 'BDU'. $184 \mathrm{pp}$.

61. Meleško, V. Očerki agrarnoj istorii Vostočnoj Belorussii (Vtoraja polovina XVII - XVIII v.). 'NT'. $248 \mathrm{pp}$.

62. Ostrowski, W. About the Origin of the Name 'White Russia'. London. 40 pp. Maps. Ill.

*::* Padpolnyja pieryjadyčnyja vydańni na Bielarusi. See no. 11.

63. Parecki, J. Symon Budny. 'BDU'. 168 pp.

64. Petrikov, P. Revkomy Belorussii. 'NT'. 288 pp.

65. Polnoje sobranije russkich letopisej. t. 32. Chroniki: Litovskaja i Žomojtskaja, Bychovca; Letopisi: Barkulabovskaja, Averki i Pancyrnogo. Ed., comp. and annot. by N. Ulaščik. 'Nauka', Moscow. 234 pp.

66. Pomniki staražytnaj bielaruskaj piśmiennaści. Ed., introd. and annot. by A. Koršunaŭ. 'NT'. $248 \mathrm{pp}$. (Texts of the letters of Filon Kmita, and the Chronicle of Barkułabava.)

67. Romanovskij, V. Protiv fal'sifikacii istorii Belorussii perioda Velikoj otečestvennoj vojny. 'NT'. $128 \mathrm{pp}$.

68. Stychov, G. Drevnij Polock. 'NT'. 136 pp. Ill.

69. Zverugo, J. Drevnij Volkovysk. 'NT'. 144 pp. Ill.

\section{Law. Politics}

70. Bialkoŭ, V., Zaleski, J. Sielskija, pasiałkovyja Saviety $i$ achova ziamielnych uhodździaŭ. 'B'. $64 \mathrm{pp}$.

71. Cahina, L. Paŭnamocny pradstaŭnik. 'B'. 112 pp.

72. Graždanskoje pravo BSSR. t. 1. Ed. by V. Cigir. 'BDU'. 384 pp.

73. Kodeks zakonov o trude Belorusskoj SSR. 'B'. 144 pp.

74. Kapuścin, A. Sud vyrašyŭ. 'B'. 103 pp.

75. Pieršaja siesija Viarchoŭnaha Savieta Bietaruskaj SSR Dzievataha sklikañnia 24-25 lipienia 1975 hoda. Stenahrafiěnaja spravazdača. 'B'. 356 pp.

76. Sbornik normativnych aktov po semejnomu pravu. 'VS'. 244 pp.

77. Sbornik zakonov Belorusskoj SSR i ukazov Prezidiuma Verchovnogo Soveta Belorusskoj SSR. 1934-1974. V trech tomach. t. 2. 'B'. 628 pp. 


\section{Language}

78. Biełaruska-polskija izaleksy. (Materyjały dla abmierkavańnia). Ed. by H. Cychun. Akademija Navuk BSSR, Instytut movaznaŭstva imia Jakuba Kołasa. 164 pp.

*** Bardovič, A., Sakun, L. Marfiemny stoŭnik biełaruskaj movy. See no. 18.

79. Burak, L. Dałučeńnie ù sučasnaj biełaruskaj movie. 'BDU'. $256 \mathrm{pp}$.

*** Grabčikov, S. Belorussko-russkij slovar'. See no. 20.

80. Hałosnyja biełaruskaj movy. (Akustyčny analiz). Ed. by V. Martynaŭ, A. Padłužny. 'NT'. $192 \mathrm{pp}$.

Jakušaŭ, E. 'Akustyčnaja charaktarystyka słoŭnaha nacisku ŭ biełaruskaj movie' (5-53); Vyhonnaja, L. 'Usprymańnie nienacisknych hałosnych nośbitami biełaruskaj movy' (54-101); Čekman, V. 'Da charaktarystyki daǔžyni hałosnych u paŭnočna-ŭschodnich biełaruskich havorkach' (102-67); Sadoŭski, P. 'Nienacisknyja hałosnyja ŭ ruskaj movie biełarusaŭ' (168-90).

81. Haŭroš, N. Naminatyŭnyja skazy ŭ sučasnaj bietaruskaj movie. 'VS'. 96 pp.

82. Hlebka, P. Pytañni historyi, movaznaŭstva, mastactva. 'NT'. 304 pp.

83. Mayo, P. A Grammar of Byelorussian. The Anglo-Byelorussian Society \& University of Sheffield, Sheffield, 1976. $66 \mathrm{pp}$.

84. Sučasnaja bielaruskaja litaraturnaja mova. Marfałohija. Ed. by F. Jankoŭski. 'VŠ'. 264 pp.

85. Sudnik, T. Dialekty litovsko-slavianskogo pograničjja. Očerki fonologičeskich sistem. 'Nauka', Moscow. 232 pp.

86. Šatałava, L. Biełaruskaje dyjalektnaje stova. 'NT'. 208 pp.

87. Suba, P. Lekcyi pa biełaruskaj marfałohii. 'BDU'. 80 pp.

88. Uścinovič, A. Antrapanimija Hrodzienక̌čyny i Brestěyny. (XVI-XVIII stst.). 'NT'. $176 \mathrm{pp}$.

89. Z narodnaha stoŭnika. Ed. by A. Kryvicki, Ju. Mackievič. 'NT'. 352 pp.

\section{Literature}

\section{LITERARY STUDIES}

90. Discordant Voices. The Non-Russian Soviet Literatures. Ed. by George S. N. Luckyj. Mosaic Press, Oakville (Canada). 149 pp.

Stankievich, S. 'Belorussian Literature' (29-45).

91. Hapava, V. Źmienlivaje $i$ spradviečnaje. Vopyt typałahičnaha daśledvańnia biełaruskaj i polskaj 'viaskovaj prozy'. 'NT'. $192 \mathrm{pp}$.

92. Kaleśnik, U. Zorny śpieŭ. Litaraturnyja partrety, narysy, eciudy. 'ML'. $400 \mathrm{pp}$.

93. Kavalenka, V. Praha duchoŭnaści. Litaraturna-krytyčnyja artykuły. 'ML'. $256 \mathrm{pp}$.

94. Kavalenka, V. Vytoki, upłyvy, paskoranaść. Raźvićcio biełaruskaj litaratury XIX-XX stahodździaŭ. 'NT'. $336 \mathrm{pp}$.

95. Kavalenka, V. Z pazicyj sučasnaści. Ahulny praces litaraturnaha raźvićcia. 'NA'. 144 pp.

96. Kazieka, J. Hotas času. Artykuły, litaraturnyja partrety .'ML'. 384 pp.

97. Lepiešaŭ, I. Frazieałohija ŭ tvorach K. Krapivy. 'NT'. 152 pp.

*** Litaratura i mastactva BSSR 1973. See no. 8.

98. Matrunionak, A. Psichałahičny analiz $i$ stanaŭleńnie biełaruskaha ramana. 'NT'. 304 pp.

99. Mielež, I. Žyćciovyja klopaty. Artykuły, ese, interv'ju. 'ML'. 608 pp.

100. Mušynski, M. Biełaruskaja krytyka $i$ litaraturaznaŭstva. 20-30-ja hady. 'NT'. $376 \mathrm{pp}$.

101. Perkin, N. Ċelovek $v$ sovetskom romane. Nekotoryje aspekty problemy. 'NT'. $304 \mathrm{pp}$.

102. Piatrovič, S. Jakub Kolas i bielaruski teatr. 'ML'. 192 pp. Ill.

*** Piśmieńniki-jubilary. See no. 13.

*** Starejšyna bielaruskaj litaratury. See no. 15.

103. Slach paeta. Zbornik uspaminaŭ i bijahrafičnych materyjałaŭ pra Maksima Bahdanoviča. Comp. by N. Vatacy. 'ML'. $332 \mathrm{pp}$.

104. Taki jon byŭ. Uspaminy pra Janku Kupału. Comp. by (. Žydovič. 'ML'. 364 pp.

*** Vobraz žančyny $\breve{u}$ tvorach biełaruskich piśmiennikaŭ. See no. 16. 


\section{ANTHOLOGIES AND WORKS OF INDIVIDUAL AUTHORS}

105. Arabiej, Lidzija. Vybranaje. Apovieści, apaviadańni. 'ML'. 368 pp.

(Part of the series Biblijateka bielaruskaj prozy.)

106. Astrejka, Anatol. Cvicicie, vierasy. Liryka. 'ML'. 176 pp.

107. Baradulin, Ryhor. Sviata pčały. Staronki z knih. Vybranyja vieršy i paemy. 'ML'. 400 pp.

108. Barski, Aleś. Moj bierah. Vieršy. 'ML'. $96 \mathrm{pp}$.

109. Bažko, Aleś. Suładździe. Paezija. 'ML'. 112 pp.

110. Bialevič, Anton. Soncam zaručonyja. Vieršy i paema. 'ML'. 128 pp.

111. Broŭka, Piatruś. I ŭdzień i ŭnočy ... Novaja kniha liryki. 'ML'. 178 pp.

112. Bryl, Janka. Swiat daleki $i$ bliski. Transl. from Byelorussian by E. Rojewska. PIW, Warsaw, 1974. 272 pp. (Short stories.)

113. Bykaŭ, Vasil. Voǔčaja zhraja. Apovieść. 'ML'. 144 pp.

114. Bykow, Wasilij. Doczekać do switu. Kruhlański most. Obelisk. Transl. from Byelorussian by J. Litwiniuk, W. Woroszylski. PIW, Warsaw, 1974. 334 pp.

115. Chadkievič Taras. Pieśnia Dźviny. Raman. 'ML'. 480 pp.

116. Chomcanka, Vasil. Vybranaje. 'ML'. 322 pp. (Part of the series Biblijateka bielaruskaj prozy.)

117. Chrestamatyja pa historyi bietaruskaha teatra i dramaturhii. U dvuch tamach. Comp., introd. and annot. by A. Sabaleŭski. 'VS'. Ill.

Tom 1: Daravalucyjny pieryjad. $336 \mathrm{pp}$.

Tom 2: Saviecki pieryjad. 512 pp.

118. Cvirka, Kastuś. Kałasy. Vieršy. 'ML'. 128 pp.

119. Črnuševič, Ničypar. Vybranyja vier šy. 'ML'. $162 \mathrm{pp}$.

120. Corny, Kuźma. Treciaje pakaleńnie. Raman. 'NA'. 256 pp.

121. Corny, Kuźma. Zbor tvoraŭ u vaśmi tamach. Gen. eds. V. Barysienaka et al. 'ML'.

Tom 7: Pjesy, niaskončanyja ramany i apovieści. Ed. by V. Barysienka. Prep. of texts and notes by A. Atajeva and A. Charkievič. 584 pp. Ill. Tom 8: Publicystyka 1923-1944, dziońnik, letapis žyćcia i tvorčaści. Ed. by A. Adamovič. Prep. of texts and notes by M. Tyčyna, chronological table by R. Hulman. $616 \mathrm{pp}$. Ill.

122. Damaševič, Uładzimir. Poracham pachla ziamla. Apovieść-chronika. 'ML'. $368 \mathrm{pp}$.

123. Dzień paezii 1975. Novyja vieršy, ankieta vohniennych hadoŭ, pra paeziju i paetaŭ. Ed. by M. Aǔramčyk et al. 'ML'. 298 pp. Ill.

124. Hardziej, Viktar. Kasavica. Vieršy. 'ML'. 80 pp. (Part of the series Pieršaja kniha paeta.)

125. Harecki, Maksim. Vybranyja Tvory. Apaviadańni i apovieść Dźvie dušy. 'Biełarus', New York. 160 pp.

126. Haŭryłkin, Leanid. Nie mahu biez ciabie. Raman. 'ML'. $336 \mathrm{pp}$.

127. Hilevič, Nił. Zapavietnaje. Liryka. 'ML'. $192 \mathrm{pp}$. (Part of the series Biblijateka bietaruskaj paezii.)

128. Hlebka, Piatro. Vieršy. 'ML'. 192 pp. (Part of the series Biblijateka bietaruskaj paezii.)

129. Hrachoŭski, Siarhiej. Rańni śnieh. Apovieść. 'ML'. 176 pp.

130. Hračanikaŭ, Anatol. Načnaja źmiena. Vieršy. 'ML'. $130 \mathrm{pp}$.

131. Hramyka, Michajła. Kala terasy. Drama ŭ 4-ch dziejach z časoŭ 1917 h. 'ML'. 88 pp. (Part of the series Biblijateka bielaruskaj dramaturhii.)

132. Hrodnieŭ, Mikoła. Sto skažuć ludzi. Apovieści. 'ML'. 320 pp.

133. Jankoŭski, Fiodar. Abrazki. 'ML'. 144 pp.

134. Jaraševič, Eduard. Praktyka ŭ Vierbičach. Apovieści. 'ML'. 224 pp.

135. Kałačynski, Michaś, Kniha družby, Liryka 'ML'. 176 pp. (Part of the series Biblijateka bietaruskaj paezii.)

136. Kałodziežny, Leanid. Aŭsiany zvon. Apaviadańni. 'ML'. 128 pp.

137. Kamaroŭski, Michaś. Pačatak. Vieršy. 'ML'. $56 \mathrm{pp}$. (Part of the series Pieršaja kniha paeta.)

138. Karpaŭ, Uładzimir. Sotaja maladość. Raman. 'ML'. 424 pp. (Part of the series Bielaruski raman.)

139. Karšukoŭ, Jaŭhień. Zmoŭščyki. Apoviesć. 'ML'. 72 pp. (For young people.) 
140. Kołas, Jakub. Novaja ziamla. Paema. 'NA'. 336 pp. Ill.

141. Kołas, Jakub. Zbor tvoraŭ u čatyrnaccaci tamach. Gen. eds. V. Barysienka et al. 'ML'. IIl.

Tom 8: Na prastorach žyćcia, Adščapieniec, Dryhva. Ed. by V. Barysienka. Prep. of texts and notes by R. Hulman and A. Charkievič. $480 \mathrm{pp}$. Tom 9: Tryłohija Na rostaniach. Ed. by J. Pšyrkoŭ. Prep. of texts and notes by S. Zabrodzkaja. 800 pp.

142. Krapiva, Kadrat. Zbor tvoraŭ u piaci tamach. 'ML'.

Tom 3: Pjesy. 328 pp.

Tom 4: Apaviadańni, feljetony, pamflety, raman. $360 \mathrm{pp}$.

143. Krupieńka, Jaŭhień. Buśliny čovien. Liryka. 'ML'. 112 pp.

144. Krušyna, Ryhor. Sny i mary. New York, München. $112 \mathrm{pp}$. (Poetry.)

145. Kudraviec, Anatol. Dzień pierad śviatam. Apaviadańni. 'ML'. $160 \mathrm{pp}$.

146. Kulašoŭ, Arkadź. Zbor tvoraŭ u piaci tamach. 'ML'.

Tom 2: Paemy. 304 pp.

Tom 3: Hroznaja pušča, Daloka da akijana. $304 \mathrm{pp}$.

147. Kulinovič, Michaś. Daroha ǔ leta. Vieršy. 'ML'. $64 \mathrm{pp}$. (Part of the series Pieršaja kniha paeta.)

148. Kupała, Janka. Tarasova dola. 'ML'. 72 pp. Ill. (Miniature luxury edition of Kupała's poem about Taras Sevčenko. Text in Byelorussian, followed by translations into Russian and Ukrainian.)

149. Kupała, Janka. Zbor tvoraŭ u siami tamach. Gen. eds. V. Barysienka et al. 'NT'.

Tom 6: Dramatyčnyja tvory, paemy, pjesy. Ed. by V. Barysienka. Prep. of texts and notes by R. Hulman.

150. Łoś, Jeǔdakija. Liryka. 'ML'. $176 \mathrm{pp}$. (Part of the series Biblijateka bielaruskaj paezii.)

151. Eužanin, Maksim. Jak naradžaŭsia novy śviet. Paema. 'ML'. 160 pp.

152. Makal, Piatruś. Dotyk ziamli. Kniha paezii. 'ML'. 160 pp.

153. Marcinovič, Pavieł. Pradvieśnie. Vieršy. 'ML'. 112 pp. (Part of the series Pieršaja kniha paeta.)

154. Mašara, Michaś. I pryjdzie čas ... Raman. 'ML'.248 pp.

155. Maŭr, Janka. Zbor tvoraŭ u čatyroch tamach. Ed. by V. Vitka et al. 'ML'. Vols. 1, 2, 3. 388, 416, 384 pp.

156. Melesch, Ivan. Menschen im Sumpf. Roman. Transl. from Byelorussian by H. Bereska, G. and W. Tschepego. Verlag 'Volk und Welt', Berlin, 1974. 519 pp. (German version of Mielež's novel Ludzi na batocie.)

157. Melezh, Ivan. La gente de la cienaga. Transl. from Russian version by C. Astor. Introd. by G. Martirosian. 'Progress', Moscow. $456 \mathrm{pp}$.

158. Navumienka, Ivan. Sasna pry darozie. Raman. 'ML'. $344 \mathrm{pp}$.

159. Navumienka, Ivan. Sorak treci. Raman. 'ML'. 1974. 368 pp.

160. Navumienka, Ivan. Viecier u sosnach. Raman. 'ML'. 328 pp.

161. Novikaŭ, Ivan. Da śvitańnia blizka. Dakumentalnaja apoviesć, 'ML'. 368 pp.

162. Palčeǔski, Aleś. Vybranyja tvory ŭ dvuch tamach. 'ML'.

Tom 1: Apaviadańni. $498 \mathrm{pp}$.

Tom 2: Apovieści, litaraturnyja partrety, ściežki, eciudy. $496 \mathrm{pp}$.

163. Pančanka, Pimien. Vybranaje. 'ML'. 496 pp. (Poetry.)

164. Paniźnik, Siarhiej. Karona nadziej. Liryka. 'ML'. 144 pp.

165. Paškoŭ, Hienadź. Klanovik. Vieršy. 'ML'. 64 pp. (Part of the series Pieršaja kniha paeta.)

166. Paŭłovič, Albiert. Vybranaje. Comp. and introd. by S. Alaksandrovič. 'ML'. 136 pp. Ill. (Poetry.)

167. Parachnievič, Michaś. Zara - zaranica. Apaviadańni. 'ML'. 208 pp.

168. Piankrat, Michaś. Bujan. Apaviadańni i apovieść. 'ML'. $128 \mathrm{pp}$.

*** Pomniki staražytnaj biełaruskaj piśmiennaści. See no. 66.

169. Prokša, Leanid. Za Dobrycaj rečkaj. Dakumientalnaja apovieść. 'ML'. 224 pp.

170. Prychodźka, Piatro. Liryka. 'ML'. 176 pp. (Part of the series Biblijateka bicłaruskaj paezii.)

171. Ptasznikau, Iwan. Łonwa. Transl. from Byelorussian by B. Monkiewicz. Wydawnictwo Łódzkie, Łódź. 208 pp.

172. Rakaŭ, Viktar. Pazyŭnyja .Vieršy, paemy. 'ML'. 96 pp. 
173. Ramanovič, Jaŭhień. Most. Pjesa ŭ 4-ch dziejach, 10 karcinach. 'ML'. 80 pp. (Part of the series Biblijateka bielaruskaj dramaturhii.)

174. Rudava, Valancina. Niespakoj. Apovieść i apaviadańni. 'ML'. 160 pp.

175. Sačanka, Barys. Cužoje nieba. Vuzły pamiaci. 'ML'. 352 pp.

176. Skryhan, Janka. Vybranyja tvory ŭ dvuch tamach. 'ML'.

Tom 1: Kruhi. Apovieść z adstupleńniami. $418 \mathrm{pp}$.

Tom 2: Apovieści, apaviadańni, rozdum. $384 \mathrm{pp}$.

177. Siadnioŭ, Masiej. Patu§anyja zory. New York - München. 278 pp. (Poetry.)

178. Skrypka, Michaś. Ad ściechu nie ŭciačs. 'ML'. $160 \mathrm{pp}$.

179. Stavier, Aleś. Lirnik. Vieršy. 'ML'. $80 \mathrm{pp}$.

180. Stralcoŭ, Barys. Viačerniaja płanieta. Apovieść i apaviadańni. 'ML'. 192 pp.

181. Šachovič, Miečysłaŭ. $P a$ zahadu serca. Vieršy. 'ML'. $128 \mathrm{pp}$.

182. Șamiakin, Ivan. Ekzamien na vosień. Kinaapovieści, pjesy. 'ML'. 432 pp.

183. Svied, Viktar. Dziacinstva prystań. BHKT, Białystok. 88 pp. (Poetry.)

184. Sybut, Pavieł. Karotkaj čarhoj. 'ML'. 80 pp.

185. Sycik, Uładzimir. U čas nie viarnulisia. Apaviadańni. 'ML'. 160 pp. (Science fiction.)

186. Us, Alaksandra \& Uładzimirava, Alena. Na siemnaccatym kilamietry. Dakumientalnaja apovieść. 'ML'. 112 pp.

187. Viarba, Viera. Siniaja buchta. Vieršy i paemy. 'ML'. $64 \mathrm{pp}$.

188. Viarcinski, Anatol. Zjaŭleñnie. Vieršy i paemy. 'ML'. 112 pp.

189. Volski, Artur. Vyratavalny kruh. Vieršy. 'ML'. $80 \mathrm{pp}$.

190. Zahorskaja, Nina. Radar. Vieršy. 'ML', $48 \mathrm{pp}$. (Part of the series Pieršaja kniha paeta.)

191. Zarecki, Michaś. Pačatak šcaścia. Vybranyja apaviadańni. 'ML'. 378 pp. (Part of the series Biblijateka bietaruskaj prozy.)

192. Zubrycki, Eduard. Blakitnyja kazki. Vieršy. 'ML'. 48 pp. (Part of the series Pieršaja kniha paeta.)

193. Zujonak, Vasil. Nača. Liryka. 'ML'. 256 pp.

194. Žuk, Aleś. Palavańnie na starych aziorach. Apaviadańni i apovieści. 'ML'. $208 \mathrm{pp}$.

195. Žyčka, Chviedar. Partyzanski praspiekt. Paema. 'ML'. 64 pp.

\section{ESSAYS. MEMOIRS}

196. Kłaz, Ilja. Pa Dźvinie na viosłach. Narys. 'ML'. 144 pp. Ill.

197. Mašara, Michaś. Staronki letapisu. Kniha ǔspaminaǔ. 'ML'. $288 \mathrm{pp}$.

198. Sabalenka, Raman. Kolerami viasiotki. Narysy. 'ML'. 128 pp.

199. Ulodzimirava, Alena. Treciaja siastra. 'B'. $96 \mathrm{pp}$.

\section{Philosophy}

*** Parecki, J. Symon Budny. See no. 63.

200. Platon. Vybranyja tvory. Protagoras, Hippias vialikšy. Transl. and annot. by J. Piatroŭski. Gainesville (USA). $171 \mathrm{pp}$.

\section{Art. Architecture}

201. A. M. Zaśpicki. Ed. by H. Padbiareski. Text by J. Sachuta. 'B'. 16 pp. Ill. (Sculptor A. Zaśpicki.)

202. Daraševic Fiodar Ivanavič. Ed. by H. Padbiareski. 'B'. 14 pp. Ill. (Painter F. Daraševič.)

203. Ivan Ničyparavič Stasievič. Ed. by H. Padbiareski. Text by L. Tarasava. 'B'. 16 pp. Ill. (Painter I. Stasievič.)

204. Jaŭhienij Dźmitryjevič Nikałajeŭ. Ed. by H. Padbiareski. Text by P. Karpac. 'B'. 16 pp. Ill. (Painter J. Nikałajeŭ.)

205. Mastak $i$ sučasnaść. Artykuły. Ed. by U. Bojka et al. 'ML'. 204 pp. Ill. Azhur, Z. 'Zmiest Času' (7-15); Hramyka, V. 'Adčuvańnie nerva rodnaj ziamli' (16-22); Krukoǔski, M. 'Estetyčnaje vychavańnie, hramadstva i Čałaviek' (23-33); Surski, A. 'Stanaŭleńnie manumientalnaj škoły' (95-102); Zaboraŭ, M. 'Mastak i styl' (129-50); Biełavusaŭ, A. 'Suviaź času' (117-815; Savicki, M. 'Stvaryć karcinu ... heta — ciažka' (182-6); Eatun, Z. 'Kazki na malbiercie' (187-91).

206. Ran Łazar Saułavič. Ed. by H. Padbiareski. Text by H. Saura. 'B'. 14 pp. Ill. (Painter E. Ran.) 
207. Śmataŭ, V. Alesia Paśladovic. 'B'. 48 pp. Ill. (Painter A. Paśladovič.)

208. Smataŭ, V. Bielaruskaja hrafika 1917-1941 hh. 'NT'. 120 pp. Ill.

209. Šnyparkoŭ, A. Piotr Sierapionavič Krachaloŭ. 'B'. 32 pp. Ill. (Painter P. Krachaloŭ.)

210. Voinov, A. Istorija architektury Belorussii. Sovetskij period. 'VS'. 216 pp. Ill.

\section{Music. Theatre. Cinema}

211. Abielijovič, L. Ramansy. 'B'. 32 pp. Mus. notes.

212. Ad pieśni da pieśni. Ed. by T. Dziadziuška. 'B'. 32 pp. Mus. notes (Part of the series Mastackaj samadziejnaści.)

213. Antalohija biełaruskaj narodnaj pieśni. 2nd enlarged ed. Comp., introd. and annot. by H. Citovič. 'B'. 616 pp. Mus. notes.

214. Bielaruś - maja pieśnia. Zbornik piesień. Ed. by D. Žuraŭloŭ. 'B'. 64 pp. Mus. notes.

215. Biełaruskaja muzyka. Vyp. 1. Ed. by T. Dziadziuška, L. Kurbieka. 'B'. 80 pp. Mus. notes, Ill.

Hłuščanka, H. 'Nacyjanalnaje i internacyjanalnaje ŭ biełaruskaj savieckaj muzycy' (3-13); Rakava, A. 'Apierety J. Siemianiaki' (14-23); Aładava, R. 'Ab polifanizacyi faktury ŭ biełaruskaj simfaničnaj muzycy druhoj pałaviny 50-60 hadoŭ' (24-33); Zubryč, I. 'Cil Ulenšpihiel J. Hlebava' (34-43); Kaleńka, R. 'Ab zjavie dyjałahičnaści ŭ biełaruskaj narodnaj i prafiesijanalnaj muzycy' (44-56); Nazina, I. 'Natatki pra biełaruskija dudki' 57-71); Scarbakova, T. 'Dziesiataja simfonija M. Aładava' (72-79).

216. Bondareva, E. Vremja, ekran, kritika. Problemy sovremennogo belorusskogo kinoiskusstva i kinokritiki. 'BDU'. $256 \mathrm{pp}$.

217. Chorovoj koncert. Ed. by D. Zuravlev. 'B'. 72 pp. Mus. notes. (Part of the series Mastackaj samadziejnaści.)

218. Chrestamatyja pa bielaruskaj charavoj opiernaj litaratury. Comp. by V. Roŭda. 'B'. 160 pp. Mus. notes.

*** Chrestamatyja pa historyi bielaruskaha teatra i dramaturhii. See no. 117.

219. Kaminskij, D. Preljudii i fugi dlja fortepiano. 'B'. 64 pp. Mus. notes.

220. Kostjukovec, L. Kantovaja kul'tura v Belorussii. Massovyje kanty-gimny, liriCeskije kanty-psal'my. 'VŚ'. 96 pp. illustr.

221. Krasinskij, A. Fil'my, geroi, vremja. (Nekotoryje tendencii razvitija sovremennogo belorusskogo kinoiskusstva). 'NT'. $160 \mathrm{pp}$. Ill.

*** Mastak $i$ sučasnaść. See no. 205.

Bondarava, E. 'Kali piśmieńnik - knihadramaturh' (34-50); Ładyhina, A. 'Kampazitar i falkłor' (51-67); Burjan, B. 'Abličča - asoba - hieroj' (6894); Arłova, T. 'Teatr u žyćci horada' (103-14); Niačaj, V. 'Ekran i duchoŭny śviet sučaśnika' (115-28); Michajłava, S. 'Sacyjalnaja pazicyja mastaka' (151-65); Hryharjanc, A. 'Niekalki dumak pra sučasnuju scenahrafiju' (166-76.)

222. Padkavyraŭ, P. Vakalnyja tvory. 'B'. 32 pp. Mus. notes.

*** Pieśni na slovy $A$. Rusaka. Ed. by D. Żuraŭloŭ. 'B'. 48 pp. Mus. notes. (Part of the series Mastackaj samadziejnaści.)

224. Pukst, R. Ramansy. 'B'. 32 pp. Mus. notes.

*** Rukovoditeljam muzykal'nych kollektivov. See no. 14.

225. Smol'skij, D. U každogo jest' svoja pesnja. 'B'. 64 pp. Mus notes. (Part of the series Mastackaj samadziejnaści.)

226. Spiavajuć 'Piesniary'. Comp. by A. Moler. Introd. by H. Zaharodni. 'B'. 64 pp. Mus. notes.

227. Syrma, R. Pieśnia - duša naroda. Publicystyka, falkłor, muzyka, litaratura. 1929-1939, 1944-1974. Ed. by N. Hilevič Comp., annot. by V. Litvinka. 'ML'. 430 pp. Ill.

\section{Press. Radio. Television}

228. Havoryć i pakazvaje Bielarus. 'B'. 240 pp. Ill.

229. Kucera, H. Rajonnaja ù pošuku. 'BDU', 1974, 128 pp.

230. Nesterovič, V. Auditorija - vsja respublika. Belorusskoje radio i kommunističeskoje vospitanije trudjašcichsja, 1945-1974. 'B'. $200 \mathrm{pp}$.

231. Pyžkoŭ, V. Ad partreta sučaśnika da historyi sučasnaści. Nadzionnyja prablemy dziejnaści biełaruskaj presy siamidziesiatych hadoù. 'BDU'. $200 \mathrm{pp}$. 


\section{ARTICLES}

\section{Abbreviations of Periodical Titles}

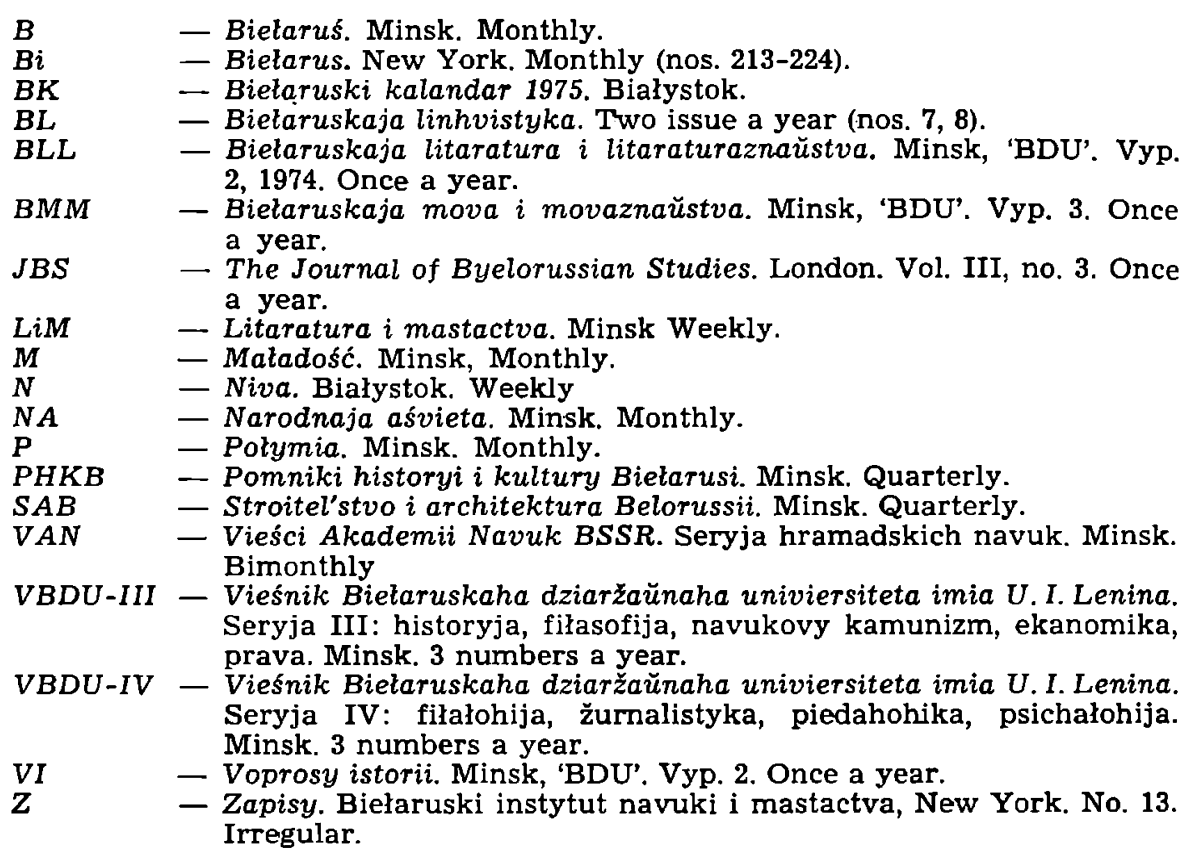

\section{Bibliography. History of Printing}

1. Nadson, A. 'Novyja nabytki Biełaruskaj biblijateki'. Božym šlacham (London), 3-4, pp. 4-8.

2. Nadson, A. 'Selected Bibliography on Byelorussia 1974'. JBS, 302-21.

3. Tumaš, V. 'Drukarnia Piotry Mścisłaŭca'. Da 400-hodździa vilenskaha Jevanhiella. $Z, 3-29$.

4. Tumaš, V. 'Drukarnia Ciapinskaha'. Da 400-hodździa dziejnaści. Z, 70-6.

\section{Archaeology}

5. Hurevič, F. 'Ramieśniki staražytnaruskich haradoŭ Paniamońnia'. PHKB, $3,34-8$.

6. Isajenka, U., Ceška, V. 'Staražytnyja pryłady pracy'. PHKB, 1, 33-6.

7. Kołabava, I. 'Ramieńnikaŭski manietny skarb'.PHKB, 3, 42-5.

8. Mikałajeŭ, M. 'Zbroja Navahrudka'. PHKB, 3, 38-40.

9. Miralubaŭ, B. 'Pinskaja visłaja piačatka'. $P H K B, 2,40-1$.

10. Mitrafanaŭ, A., Karobuškina, T. 'Archieałahičny pomnik raskazvaje'. $P H K B, 2,38-40$. (Archaeological excavations near the village of Svila Pieršaja in the district of Hłybokaje.)

11. Pobal, L., Huryn, M. 'Zaleznyja vyraby z Tajmanava Bychaǔskaha rajona'. $V A N, 2,101-9$.

12. Pobal, L., Sierhačoŭ, S. 'Słavianskaje žyllo Biełarusi (na materyjałach sielašča ŭ Tajmanavie Mahiloŭskaj vobłaści)'. VAN, 3, 88-93.

\section{Education. Culture}

13. Cukierman, A. 'Vučeńnie Mikałaja Kapernika ǔ Biełarusi (kaniec XVII 60-ja hady XVIII st.). VAN, 4, 75-83.

14. Cikalov, R. 'Razvitije material'noj bazy obščeobrazovatel'nych škol BSSR v 1959-1965 gg.'. VI, 108-14. 
15. Firsava, K. 'Farmiravańnie navukovaha Śvietapohladu ŭ studentaŭ vyšejšych navukovych ustanoŭ, navučencaŭ technikumaŭ i vučyliščaŭ (19591965 hh.)'. VAN, 5, 61-70.

16. Gnievka, N. 'Vosstanovlenije i dal'nejšeje razvitije obščeobrazovatel'nych škol v BSSR v četvertoj pjatiletke (1946-1950 gg.)'. VI, 14-21.

17. Hałubovič, V. 'Udzieł Biełaruskaj SSR u raźvićci saviecka - vienhierskaha supracoŭnictva ŭ halinie narodnaj aśviety (1960-1974)'. VAN, 3, 47-55.

18. Kamienskaja, $N$. 'Iz istorii bor'by $s$ negramotnost'ju v Belorussii v pervyje gody Sovetskoj vlasti (1917-1920 gg.)'. VI, 41-55.

19. Lašuk, V. 'Śkolnaje krajaznaŭstva Biełarusi 20-30ch hadoǔ'. BLL, 139-48.

20. Sestakova, T. 'Iz istorii meždunarodnych naučnych i kul'turnych svjazej Sovetskoj Belorussii v 30-je gody'. VI, 114-25.

21. Sybieka, Z. 'Prajekty VNU ŭ darevalucyjnym Minsku'. PHKB, 2, 46-8.

\section{TEACHING OF BYELORUSSIAN LANGUAGE AND LITERATURE}

22. Alachnovič, P. 'Mastackaje čytańnie i ilustracyja pry vyvučeńni paemy Novaja ziamla'. NA, 7, 37-41.

23. Choład, I. 'Uroki praktyčnaj stylistyki ŭ IX kłasie'. NA, 8, 65-73; 10, 50-61; $11,43-7$.

24. Fiadosik, A. 'Vykarystańnie falkłoru ŭ vučebna-vychavaŭčaj rabocie'. $N A$, $1,55-60$.

25. Kabržyckaja, T. 'Vyvučeńnie dramaturhičnych tvoraŭ'. $N A, 11,54-59$.

26. Kaścian, M. 'Elemienty prahramiravanaha navučańnia na ǔrokach movy'. $N A, 11,48-53$.

27. Kraŭcova, K. 'Ab novaj prahramie i zađačach vykładańnia litaratury'. $N A$, $8,55-9$.

28. Lašuk, V. 'Uroki pazakłasnaha čytańnia ŭ VIII-X kłasach'. NA, 8, 60-4.

29. Lepiešaŭ, I. 'Frazieałahičny słoŭnik na ŭrokach movy i litaratury'. $N A, 6$, 54-9.

30. Lepiešaŭ, I. 'Z uvahaju da słova: analiz movy mastackich tvoraŭ u škole'. $P, 10,213-21$.

31. Mišcanð̌uk, M. 'Pierapiska z ziamloj. Tvorčaść M. Tanka ŭ X kłasie'. NA, $12,52-8$.

32. Protcanka, V., Łaŭrel, J. 'Vyvučeńnie biazzłučnikavych składanych skazaŭ'. $N A, 2,55-62$.

33. Protčanka, V., Łaŭrel, J. 'Vyvučeńnie kanstrukcyj z prostaj i ŭkosnaj movaj'. $N A, 3,50-6$.

34. Protčanka, V. 'Uzajemasuviaź analizu i sintezu pry vyvučeńni składanazaležnaha skaza'. $N A, 10,56-61$.

35. Protčanka, V. 'Niekatoryja pytańni vyvučeńnia adnarodnych členaŭ skaza'. $N A, 12,47-51$.

36. Trajkoŭskaja, V. 'Vyvučeńnie temy "Antonimy" ŭ IV kłasie'. NA, 7, 33-6.

\section{TEACHING OF HISTORY OF BYELORUSSIA}

37. Hnieŭka, M. 'Siužety z historyi Biełarusi ŭ IV kłasie'. NA, 9, 61-5.

38. Hnieŭka, M. 'Vykarystańnie mastackaj litaratury na ŭrokach historyi BSSR (VIII kłas). NA, 2, 72-5; 3, 72-6; 4, 79-82.

39. Hneŭka, M. 'Vykarystańnie mastackaj litaratury na ŭrokach historyi BSSR (IX kłas)'. $N A, 10,68-74 ; 11,60-5 ; 12,73-80$.

\section{Ethnography. Folklore}

40. 'Falkłor'. $N$, nos. 1-16, 18-52. (Short publications of Byelorussian folk songs from the eastern part of Białystok region, collected by M. Hajduk. Mus. ed. L. Pańko.)

41. Hajduk, M. 'Krajaznaŭčy słoŭnik'. $N$, nos. 2, 7, 16, 21, 24, 28, 37, 42, 48, 52. (Short articles on the villages Achrymy, Anusin, Alchovičy, Alšanka, Astrovak, Alchoŭka, Alchovaja Kładka, Alšyna, Apaka Vialikaja, Achremičy.)

42. Hajduk, M. "'Oj, łožo, łožo, chto na tobie laža ..."'. $N, 8,3$. (Folk singers Nadzieja Hrycak and Maryja Juroviec from the village of Navasiołki.)

43. Majduk, M. “"Oj, puojdu ja puod liesok na časok..."' $N, 17,4-5$. (Folk songs from the village of Areškava, and their singers.) 
44. Hovar, V. 'Zahadka Paleśsia'. $M, 1,179-86$. (Folk art of Paleśsie.)

45. Jakimovič, J. 'Draŭlanaje dojlidstva biełaruskaha Paleśsia pa invientarach XVI - pieršaj pałaviny XIX st.' VAN, 4, 93-101.

46. Kisialoŭ, U. 'Voźnicki promysł u Minsku'. BHKB, 3, 52-5.

47. Leanovič I. 'Žyllo rabočych h. Minska ŭ paślavajenny i sučasny pieryjad'. $V A N, 3,78-87$.

48. Łoban, B. 'Skarb'. $M, 12,176-84$. (Corn dollies and straw incrustation.)

49. Naścienka, Z. 'Cymbały'. $P H K B, 2,50-2$.

50. Ramaniuk, M. 'Śviatočnyja stroi žančyn Mazyrščyny'. PHKB, 4, 54-9.

51. Ramaniuk, M. 'Viasiołki ŭ padarunak. Stroi žančyn Paleśsia'. M, 12, 176-84.

52. Sachuta, J. 'Da historyi mastackaha azdableńnia biełaruskaj narodnaj mebli'. VAN, 6, 119-28.

53. Sachuta, J. 'Dekaratyŭnaja raźba ŭ sialanskim pobycie (XIX — pačatku $\mathrm{XX}$ st.)'. VAN, 4, 93-101.

54. Sachuta, J. 'Takarnyja vyraby'. PHKB, 1, 47-9.

\section{History}

55. Asmałoŭski, V. 'Ab partyjnym sastavie Savietaŭ Biełarusi ŭ druhoj pałavinie 1918 h.'. VAN, 2, 42-9.

56. Baranoŭski, L. 'Zarabotnaja płata i siemiejny biudžet čyhunačnikaŭ Biełarusi kanca XIX - pačatku XX st.'. VAN, 6, 109-18.

57. Bierhman, A. 'Hramada praz 50 hod'. BK, 142-59.

58. Burakoŭskaja, N. 'Adychodnyja promysły sialan-biełarusaŭ u pieryjad raspadu fieadalizmu i pačatku kapitalismu'. VAN, 4, 110-20.

59. Carjuk, I. 'Obrazovanije v zapadnych oblastjach Belorussii vremennych organov vlasti i ich dejatel'nost' (sentjabr' 1939 - mart 1940 g.)'. VI, 167-74.

60. Chachłoŭ, A. 'Z historyi dziejnaści KPB u baraćbie z kontrrevalucyjaj ŭ $1921 \mathrm{~h} . \therefore$. VAN, 1, 30-41.

62. Deško, I. 'Kommunističeskaja partija Zapadnoj Belorussii vo glave bor'by trudjaščichsja mass za mir i zaščitu Sovetskogo Sojuza (1935-1938 gg.)'. VI, 174-84.

63. Dubinina, L. 'Rola paŭpredstva BSSR u ažyciaŭleńni fiederatyŭnych znosin pamiž BSSR i RSFSR (1921-1922 hh.)'. VAN, 4, 30-8.

64. Hrabionkina, A. 'Idejna-palityčnaje vychavańnie žančyn zachodnich abłaściej BSSR u paślavajennyja hady (1946-1950 hh.)'. VAN, 2, 75-84.

65. Hryckievič, A. 'Historyja kupli Słucka'. PHKB, 2, 42-3.

66. Kachanoŭski, H. 'Zbiralnictva i achova pomnikaŭ u XVIII st. na Biełarusi'. PHKB, 2, 44-5.

67. Krajcar, J. 'The Last Princes of Słuck'. JBS, 269-87.

68. Kraǔčanka, P. 'Źniešniehandlovyja suviazi BSSR u peryjad stvareńnia ekanamičnaha fundamientu sacyjalizmu (1926-1932 hh.)'. VBDU-III, 1, 16-21.

69. Kravčenko, P. 'Vnešnjaja torgovlja BSSR v period vosstanovlenija narodnogo chozjajstva (1921-1925 gg.)'. VI, 135-44.

70. Kuprejeva, A. 'Dapamoha nasielnictva Biełarusi frontu (vierasień 19431945 hh.)'. VAN, 4, 30-8.

71. Leščanka, R. 'Bychaŭ u hady Paŭnočnaj vajny'. $P H K B, 3,4112$.

72. Maksimovič, R. 'Histaryčnaja kancepcyja Vacłava Łastoŭskaha ŭ pracach sučasnych historykaŭ'. $Z, 47-56$.

73. Maksimovič, R. 'Sprečka pra dakumienty, jakich nikoli nia było'. Z, 77-81. (The question of the language of certain 17th century documents.)

74. Paniucič, V. 'Tankarunnaja aviečkahadoŭla ŭ pamieščyckaj haspadarcy Biełarusi ŭ druhoj pałavinie XIX st. (1861-1900 hh.)'. VAN, 4, 84-92.

75. Pavljučenko, N. ' $\mathrm{K}$ voprosu o reakcionnaj roli pravoslavnoj cerkvi $v$ Belorussii v period revoljucii 1905-1907 gg.'. VI, 184-91.

76. Polonskij, A. 'Nekotoryje aspekty social'no - ekonomičeskoj politiki carizma $v$ Belorussii perioda razloženija i krizisa krepostnogo stroja'. VI, 78-84.

77. Piakarski, A. 'Hierby byłych namieśnictvaŭ, hubierniaŭ i ich centraŭ'. PHKB, 3, 50-2.

78. Rajski, U. ' $\mathrm{Z}$ historyi mietałapramysłovaści Biełarusi (1926-1932 hh.'). VAN, $4,84-92$.

79. Rjabov, A. 'Iz istorii organizacionno-chozjajstvennogo ukreplenija kolchozov Belorussii (1933-1940 gg.)'. VI, 191-7. 
80. Ruban, A. 'Supracoŭnictva i ŭzajemadapamoha RSFSR, BSSR i USSR u stvareńni materyjalnaj bazy sielskaj haspadarki ŭ hady pieršaj piacihodki'. VAN, 3, 41-6.

81. Snarski, I. 'Jana ŭskalychnuła narod'. $N, 25,1$ \& 4-5. (50 years of the Byelorussian Socialist Hramada.)

82. Stukanov, A. 'Material'naja pomošč' trudjaščichsja Belorussii Krasnoj Armii v 1919 g.'. VI, 156-67.

83. Saŭkaplas, V. 'Paviatovyja ziemskija sudy ŭ Biełarusi (1796-1831 hh.)'. $V B D U-I I I, 1,16-21$.

84. Sorachaŭ, J.' 'Pry vytokach biełaruskaj savieckaj archieahrafii'. PHKB, $4,59-60$.

85. Treščenok, J. 'Obščaja charakteristika i osnovnyje principy istoričeskoj kritiki dokumental'nych materialov CGAOR BSSR kak istorii rabočego klasa Belorussii perioda pervoj pjatiletki'. VI, 215-22.

86. Višnevskij, A. 'Manufakturnoje proizvodstvo gorodov Belorussii v 30-50-ch godach XIX v.'. VI, 8-14.

87. Vitan, K. 'Hazeta "Homan"'. Z, 67-9.

88. Zagorul'skij, E. 'O načal'nom etape formirovanija slavjan'. VBDU-III, $2,24-8$.

89. Zaprudnik, J. 'Biełaruś u paru dziaržaŭnych dumaŭ Rasiei'. Z, 30-46.

91. Zaprudnik, J. 'Byelorussia's Representatives in the Second State Duma (20 Feb. -2 Jan. 1907)'. JBS, 229-43.

92. Zaprudnik, J. 'Dyplamatyčny pašpart Biełaruskaje Narodnaje Respubliki'. $Z, 99-103$.

93. Zaprudnik, J. 'Ustaŭnyja hramaty Biełaruskaje Narodnaje Respubliki'. Z, 87-98. (English translations of the documents made jointly with Th. Bird.)

\section{Language}

94. Aničenka, U. Dyjalektnaja dyfierencyjacyja staražytnaruskaj movy'. $B M M$, 3-12.

95. Aprymienie, A. 'Asablivaści dziejasłoŭnych form u Apostale F. Skaryny'. $B L, 7,32-8$.

96. Aprymienie, A. 'Niekatoryja asablivaści zajmiennych skłanieńniaŭ u Apostale F. Skaryny'. VAN, 5, 125-31.

97. Bandarenka, T. 'Da pytańnia ab kiravańni jak adnym sa sposabaŭ padparadkavalnaj suviazi słoŭ u słovazłučeńni'. $B L, 8,46-55$.

98. Calančuk, S. 'Usimi hraniami słova. Leksika-frazieałahičnaja sinanimiku u ramanie Ivana Mieleža Ludzi na bałocie'. P, 12, 237-46.

99. Chanin, M. 'Da pytańnia ab siemantyčnaj kłasifikacyi udakładniajučych členaŭ skaza (na materyjałach ruskaj i biełaruskaj moŭ)'. VAN, 1, 117-23.

100. Czekman, W. 'Akanie, istota zjawiska i jego pochodzenie'. Slavia Orientalis (Warsaw), 3, 283-305.

101. Cekman, V. 'Z nazirańniaŭ nad fanietykaj havorak Homielskaj vobłaści'. $B L, 8,31-6$.

102. Yałaj,' O. 'Da siemantyčnaha asvajeńnia niamieckich zapazyčańniaŭ u starabiełaruskaj movie'. VBDU-IV, 2, 34-8.

103. Hiermanovič, I. 'A. K. Sieržputoǔski jak movaznaviec'. VBDU-IV, 1, 30-5.

104. Hiermanovič, I. 'A. I. Krukoǔski jak movaznaviec'. VBDU-IV, 2, 39-43.

105. Hiermanovič, I. 'M. I. Kaśpiaroviě jak movaznaviec'. VBDU-IV 3, 37-45.

106. Hiermanovič, I. ' $Z$ historyi biełaruskaj knižnaj terminałohii'. $B L, 7,27-31$.

107. Hilevič, $N$. 'Dyjalektyzmy ŭ prozie biełaruskich piśmieńnikaŭ siaredniaha pakaleńnia'. BMM, 12-20.

108. 'Hîstoryka-etymałahičnyja natatki'. $B L, 7,65-70 ; 8,56-60$.

109. Horlenka, V. ' $Z$ ' havorak Homielšcyny'. $P$, 9, 248-51.

110. Hruco, A. 'Dziejasłoŭ vaditi i vytvornyja ad jaho ŭ biełaruskaj movie'. $V B D U-I V, 1,21-5$.

111. Janovič, A. 'Prysłoŭji na -'ski ŭ historyi ruskaj i biełaruskaj moŭ'. $B M M$, 143-51.

112. Jaškin, I. 'Da historyi siaredniesožskich havorak'. BMM, 151-60.

113. Jelisiejeva, I. 'Biesprynazoŭnikavaje dziejasłoŭnaje kiravańnie ŭ biełaruskaj movie XVI st.'. $B L, 7,39-45$. 
114. Karacinskaja, D. 'Siemantyěnaja dyvierhiencyja jak sposab utvareńnia amonimaŭ'. $B M M, 36-45$.

115. Kazačonak, T. 'Nazvy aharodnych raślin u starabiełaruskaj movie'. VAN, $3,114-22$.

116. Kazačonak, T., Sadurski, I. 'Sadovaja leksika starabiełaruskaj movy'. $B L$, $7,51-7$.

117. Kazłova, R. 'Dyjalektnyja nazvy damašnich žyvioł i ich pachodžańnie'. $B M M, 27-36$.

118. Kiečyk, S. 'Da pytańnia ab vida-časavych značeńniach dziejeprysłoǔja ŭ sučasnaj biełaruskaj movie'. VAN, 5, 113-20.

119. Kiečyk, S. 'Ab sintaksičnych funkcyjach dziejeprysłoŭja ŭ sučasnaj biełaruskaj movie'. VAN, 6, 71-5.

120. Kiedajtenie, $\mathrm{K}$. 'Ab leksičnych asablivaściach starabiełaruskich i staraŭkrainskich pomnikaŭ palemiěnaj litaratury XVI-XVII st.'. BMM, 46-50.

121. Klusaŭ, R. “ “... Ad rańniaje da viačerniaje zary”. Natatki pa hramatyěnaj stylistycy'. $P, 6,249-52$.

122. Kopanieŭ, P., Śubina, E. 'Da pytańnia ab hramatyčnym ciarpierašnim'. $B L$, 7, 14-21.

123. Kraśniej, V. 'Biełaruskija matematyčnyja terminy pačatku XX st.'. $V B D U-I V, 1,25-30$.

124. Kudzis, S. 'Ab stylfarmirujučych funkcyjalnych faktarach'. $B L, 7,10-13$.

125. Kušniarova, L. 'Ab suadnosinach abreviatur sa słovazłučeńniami'. VAN, $1,124-9$.

126. Lepiešaŭ, I. 'Adnaŭleńnie ŭnutranaj formy frazieałahizmu jak mastacki pryjom'. $B L, 7,22-6$.

127. Lepiešaŭ, I. 'Pomniki talentu, daścipnaści, natchnieńnia. Frazieałahizmy Kandrata Krapivy'. $P, 3,247-52$.

128. Maluk, A. 'Emacyjanalnyja asablivaści hutarkovaha słova'. BMM, 57-63.

129. Małažaj, H. 'Da etymałohii niekatorych acenačnych nazvaŭ asoby'. $B M M$, 50-7.

130. Mayo, P. 'Recent Developments in the Norms of the Byelorussian Literary Language'. JBS, 244-68.

131. Miacielskaja, E. 'Biesprynazoŭnikavyja kanstrukcyi biełaruskich narodnych havorak'. $B M M$, 81-90.

132. Miadźviedzieva, V. 'Da historyi leksiem z koraniem sok i jaho ałamorfami va ǔschodniesłavianskich movach'. $B M M, 74-80$.

133. Michnievič, A. 'Farmalnyja pryznaki sielektyŭncy značeńniaŭ'. BMM, 63-74.

134. Michnievič, A. 'Kanstrukcyjna-sintaksičnaja amanimija'. VAN, 2, 120-127.

135. Narkievič, A. 'Słovazłučeńnie jak pradmiet sintaksisa i jaho dyfierencyjalnyja adznaki'. $B M M, 90-99$.

136. Paraskovič, H. 'Strukturnyja asablivaści i stylistyčnyja funkcyi nazoŭnikavych novatvoraŭ u biełaruskich prykazkach'. VAN, 5, 104-12.

137. Parukaŭ, A. 'Słovaŭtvaralnaja sistema nazoŭnikaŭ u pierakładnych vydańniach Skaryny'. BMM, 100-7.

138. Paŭlenka, M. 'Słovaŭtvaralnaje varjiravańnie asabovych nazoŭnikaŭ u biełaruskaj movie XIX st.'. $B M M, 107-17$.

139. Paŭlenka, M. 'Adnakarennyja žanočyja Nomina agentis u starabiełaruskaj movie'. $B L, 8,10-15$.

140. Paŭlenka, M. 'Žanočyja asabovyja naminacyi ŭ biełaruskaj movie XIX pačatku XX st.'. VBDU-IV, 2, 29-33.

141. Paŭlenka, M. 'Żanočyja asabovyja nazoŭniki na $-k-a$ ŭ biełaruskaj movie XIX - pacatku XX st.'. VBDU-IV, 3, 66-71.

142. Piskun, U. 'Pra słovaŭtvaralny typ i słovaŭtvaralnuju madel'. BMM, 117-24.

143. Prychodźka, M. 'Niekatoryja pytańni dapasavańnia vykaźnika ŭ sierbacharvackaj, słavienskaj i biełaruskaj movach'. BMM, 124-32.

144. Płotnikaŭ, B. 'Statystyěnyja daśledvańni movy ŭ Biełarusi'. BL, 7, 3-9.

145. Rabienka, V. 'Biełaruskija funkcyjanalnyja adpaviedniki typałahična tojesnaj niamiecka-anhlijskaj kanstrukcyi lassen/let'. VAN, 5, 121-4.

146. Rudakoŭskaja, Z. et al. 'Materyjały dla dyjalektnaha słoŭnika Homielščyny'. $B M M, 161-260$. (Letters A-D.)

147. Saroka, U. 'Abahulniajučyja narodnyja nazvy budynkaŭ (na materyjale biełaruskich narodnych kazak)'. $V B D U-I V, 3,32-6$. 
148. Ściacko, P. 'Utvareńnie nazoŭnikaŭ pry dapamozie sufiksaŭ z elemientam -ch- u biełaruskaj narodnaj movie', $B L, 8,23-30$.

149. Skurat, K. 'Nazvy pasudzin u starabiełaruskaj movie'. BL, 8, 10-15.

150. Stankievič, A. 'Siemantyčnaje asvajeńnie leksiki hreka-łacinskaha pachodžańnia ŭ sučasnaj biełaruskaj movie'. BMM, 132-43.

151. Sviažynski, U. 'Leksičnyja elemienty polskaha pachodžańnia ŭ "Dzionniku" F. Jeŭłašoŭskaha'. $B L, 7,46-50$.

152. Sviažynski, U. 'Polska-biełaruskija fanietyčnyja interfierencyi ǔ "Dzionniku" Jeǔłašoŭskaha'. VAN, 4, 131-7.

153. Szadyko, S. 'Akcent $w$ złoženiach rzeczownikowych współczesnego języka białoruskiego'. Slavia Orientalis (Warsaw), 2, 181-5.

154. Śkraba, I. 'Da pryčyn uźniknieńnia fanietyčnych varyjantaŭ u biełaruskaj movie'. VBDU-IV, 1, 35-40.

155. Suba, P. 'Formy zaležnaha nazoŭnika ŭ spałučeńni z prynazoŭnikam $p a$ '. $B L, 8,37-45$.

156. Šba, $P$. 'Sintaksičnyja kanstrukcyi $z$ paŭtareńniem prynazoŭnika'. $V B D U-I V, 2,26-9$.

157. Viarchoŭ, P. 'Sufiksalnaja sinanimija adnakaraniovych nazoŭnikaŭ u historyi biełaruskaj movy'. VAN, 2, 110-9.

158. Zialinskaja, H. 'Dziejasłoŭnyja asnovy z prefiksam $p a-(p o-)$ va ŭschodniesłavianskich movach'. BMM, 20-7.

\section{Literature}

159. Aročka, M. 'Na vohniennym napramku'. $P, 5,202-18$.

160. Barščeŭski, A. 'Biełaruskaja litaratura'. $N$, nos. 1-4, 6-15, 19-46, 48-51. (History of Byelorussian literature, published in short instalments since 1971. The 1975 publications deal with Maksim Bahdanovič and Aleś Harun.)

161. Biečyk, A. 'Spiašajsia - pierad taboju śviet... Maładaja paezija, hod 1974. $M, 4,144-53$.

162. Bierhman, A. 'Jośc rukapis!'. $N, 26,3$. (Discovery of the autograph of B. Taraškievič's translation of Pan Tadeusz.)

163. Chromčanka, K. 'Biełaruska-ukrainskija litaraturnyja ŭzajemasuviazi 20-ch hadoŭ'. VBDU, 3, 8-15.

164. Haŭruk, J. 'Dalokaja para maładości'. LiM, 13, 6 (The literary society of the Byelorussian Agricultural Academy in the 1920s.)

165. Hilevič, N. 'U paetyčnaj majsterni. Pra hukapis i ryfmu ŭ narodnaj paezii'. $P, 3,196-231$.

166. Hniłamiodaŭ, U. 'Ludzi revalucyjnaha abaviazku. Vobraz kamunista ŭ biełaruskaj litaratury'. $P, 3,169-89$.

167. Hrynčyk, M. 'Rehijanalnyja tradycyi i tvorčaść piśmieńnika'. BLL, 22-31.

168. Hurskaja, A. 'Svabodny vierš i sučasnaja biełaruskaja paezija'. VAN, $1,89-97$.

169. Ivašyn, V. 'Partyjnaść litaratury i svaboda tvorčaści'. $P, 11,169-85$.

170. Janowicz, S. 'Kilka uwag o literaturze białoruskiej i jej recepcji w Polsce Ludowej'. Studia Polono-Slavica-Orientalia (Wrocław), Acta Literaria II, 199-211.

171. Jafimava, M. “"Nie kazkaj adzinaj...”. Słova pra sučasnuju biełaruskuju paeziju dla dziaciej małodšaha ŭzrostu'. LiM, 12, 4-5.

172. Kałubovič, A. 'Nieviadomyja apaviadańni XIV i XV stst.'. Božym šlacham (London), 3-4, 11-15.

173. Kavalenka, V. 'Krytyka - naša turbota'. LiM, 23, 6-8.

174. Kavalenka, V. 'Pazicyja piśmieńnika i duchoŭny sviet hieroja'. P. 12, 192210.

175. Kisialoŭ, H. 'Niekatoryja pytańni vyvuceńnia paemy Enieida navyvarat'. VAN, 4, 121-30.

176. Lecka, J. 'Nieŭmiručy podźvih naroda'. Hieraičnaja tema ŭ biełaruskaj prozie. $P, 5,186-201$.

177. Łaŭšuk, S. 'Kirunak pošukaŭ - sučasnaść'. Novyja pjesy biełaruskich dramaturhaŭ. $P, 2,192-204$.

178. Łaŭšuk, S. 'Prablemy asoby ŭ biełaruskaj histaryčnaj dramaturhii'. VAN, $3,93-103$. 
179. Łavyš, T. 'Niekatoryja asablivaści epiteta biełaruskaj i anhlijskaj mastackaj litaratury'. VAN, 3, 104-8.

180. Łojka, A., Pšyrkoŭ, J. 'Dojlidy novaj kultury', BLL, 3-22. (The literary association 'Uzvyšša' of the 1920s.)

181. Maldzis, A. 'Na zary novaj biełaruskaj litaratury'. BLL, 45-58. (Some unknown works of Byelorussian literature of the 18th century.)

182. 'Maładyja hałasy'. BK, 77-83. (Short autobiographical notes by the young Byelorussian poets Hieorhij Bajena, Irena Baravik, Nina Haŭryluk and Zosia Sackko from the Białystok region, and examples of their works.)

183. Navumienka, I. 'Litaratura i NTR'. $P, 8,207-16$.

184. Paźniak, Z. 'Chto takija Daleckija?'. PHKB, 1, 50-1. (The problem of the authorship of the play Michalka.)

185. Rudčyk, V. 'Mickievič i Biełaruś'. BK, 134-40.

186. Savik, L. "Tradycyi biełaruskaj "viaskovaj" prozy 20-30-ch hadoŭ i Paleskaja chronika I. Mieleža'. VAN, 5, 94-103.

187. Sakałoŭski, U. 'Niekatoryja rysy typałahičnaj ahulnaści i admietnaści hieroja ŭ biełaruskaj i niamieckaj paezii 20 - pačatku 30 -ch hadoŭ (M. Carot i I. Becher)'. VAN, 6, 90-9.

188. Skibińska-Charyło, Z. 'O przekładach Pana Tadeusza na język białoruski'. Studia Polono-Slavica-Orientalia (Wrocław), Acta Literaria II, 181-98.

189. Smalankova, L. 'Hieroika-revalucyjnaja paema 30-ch hadoŭ'. $B L L$, 58-68.

190. Saŭłoŭskaja, M. 'Hieroj i tvorčaja pazicyja dramaturha'. BLL, 87-95.

191. Skraba, R. 'Słova i vobraz'. $P, 6,227-38$.

192. Tyčyna, M. 'Dalahlad času. Maładaja proza, hod 1974'. M, 3, 166-74.

193. Zubkoŭski, B. 'Kniha $\mathrm{z}$ adrasam i biez adrasa'. P, 4, 221-31. (Byelorussian literature for children.)

BAHDANOVIC, MAKSIM

194. Bačyła, A. 'Pieršaja daradca paeta'. M. 4, 170-9.

195. Biarozkin, R. 'Bahdanovič i Puškin'. B, 6, 28-9.

196. Vatacy, N. 'Maksim Bahdanovič - Valeryju Brusavu'. PHKB, 1, 41-3.

BAHUSEVIČ, FRANCISAK

197. Kisialoŭ, H. 'Darohaju da ludziej'. $M, 8,182-9$.

198. Sodal, U. 'Nieviadomyja zdymki Franciška Bahuševiča'. LiM, 14, 16.

BARANAVYCH, SYMON

199. Kazieka, J. 'Staronka bijahrafii'. $M$, 1, 169-71.

BARADULIN, RYHOR

200. Zujonak, V. 'Nieba tvaich vačej'. $M, 2,164-75$.

BROUKA, PIATRUS

201. Hniłamiodaŭ, U. 'Dum palot uzniosły'. $P, 6,195-216$.

202. Samiakin, I. 'Na pieršaj linii'. $M, 6,159-64$.

BRYL, JANKA

203. Kazłova, V. 'Janka Bryl ab dniach viekapomnych'. VBDU-IV, 3, 3-8.

CIOTKA (ALOIZA PAŠKIEVIČ)

204. Dubiajkoŭskaja, J. 'Aloiza Paškievičanka - Ciotka'. Bi, 223, 6-7.

CORNY, KUŹMA

205. Dalidovič, $H$. ' $Z$ akna Cimkavič śviet vialiki ...' ' $M, 7,151-5$.

206. Kazieka, J. 'Ramany Kuźmy Cornaha pra vajnu'. P, 6, 217-26.

207. Żorava, K. 'Piśmy Kuźmy Cornaha'. LiM, 26, 8.

DUBOUKKA, UEADZIMIR

208. Vialuhin, A. 'Huśli na šypšynie'. $P, 7,203-9$.

DUNIN-MARCINKIEVIČ, VINCENT

209. Sodal, U. 'Los zdymka V. Dunina-Marcinkieviča'. LiM, 38,16.

210. Usikaŭ, J. 'Zmahar za mužyckuju praŭdu. Pra śvietapohlad Dunina-Marcinkieviča i jaho Sialanku'. $P, 7,224-35$.

HAEUBOK, UEADZISEAŬ

211. Mielnikava, L. 'Duchoŭny voblik hieroja'. BLL, 95-102. 


\section{HARECKI, MAKSIM}

212. Adamovič, A. " "Bramu skarbaŭ svaich adčyniaju ..."'. $P, 8,217-35 ; 9,207-$ $26 ; 10,187-212 ; 11,202-41$.

213. Łaškievič, V. 'M. Harecki dla dziaciej'. BLL, 126-39.

214. Stralcoŭ, M. 'Całaviek z Małoj Baćkaŭki'. M, 6, 173-80.

HILEVIC, NIE

215. Karatkaja, L. "'Lublu ciabie, żyćcio, luboŭju kroŭnaj ..."'. M, 4, 155-67.

HLEBKA, PIATRO

216. Hlebka, P. 'Majaankieta'. M, 7, 158-71. (Publ. by H. Hlebka.)

HRAMYKA, MICHAJEA

217. Siemianovič, A. 'Piśmieńnik, vučony, piedahoh'. B, 11, 24.

218. Suškievič, S. 'Vučony, piśmieńnik, pierakładčyk'. LiM, 14-15.

JEUĖAŠOŨSKI, FIODAR

219. Sviažynski, U. 'Aryhinał znojdzieny'. PHKB, 2, 48-9.

KLIMKOVIC, MICHAS

220. Stankievič, S. 'Nieviadomy raździeł u bijahrafii Michasia Klimkoviča'. Bi, 215,$4 ; 216,4$.

KOEAS, JAKUB

221. Mazur, U. 'U haścinnym domie paeta'. $B, 8,15-16$.

222. Žyhocki, M. 'Pieśnia muzyki. Da 50-hodździa paemy J. Kołasa Symon mu$z y k a^{\prime} . B, 7,9$.

KULAS̆OU, ARKADŹ

223. Biarozkin, R. 'Kulašoŭ i Tvardoŭski'. $M, 1,149-63$.

KUPAEA, JANKA

224. Aročka, M. 'Sproba razhadki Snu na kurhanie'. P, 7, 210-23.

225. Drozd, S. 'J. Kupała i tradycyi polskaj kłasičnaj litaratury'. $B L L$, 31-45.

LISICYN, UŁADZIMIR

226. Simanovič, D. 'Zastajecca pieśnia na ziamli'. LiM, 30, 4.

MIELEZ, IVAN

227. Buhajoǔ, D. 'Ad apaviadańnia da ramana. Stanaŭleńnie tvorčaj indyvidualnaści Ivana Mieleža'. $P, 1,194-228$.

*** Savik, L. "Tradycyi biełaruskaj "viaskovaj" prozy 20-30-ch hadoŭ i Paleskaja chronika I. Mieleža'. See no. 186.

228. Smykoŭskaja, V. 'Raman ab vialikim, viečnym . . $B L L$, 102-16.

NAVUMIENKA, IVAN

229. Buhajoŭ, D. 'Cas padrachunkaŭ'. LiM, 7, 5.

230. Jurevič, U. 'Viartańnie ŭ maładość. P, 2, 205-17.

PALCEUSKI, ALES

231. Miaževič, U. 'Talent słuchać čałavieka'. $P, 1,229-32$.

PAŰEOVIC, ALBERT

232. Bazarevič, M. " "Lublu abšar łuhoŭ pryvolnych ..." '. LiM, 46-8.

RODZIEVIC, LEAPOLD

233. Kaleśnik, U. 'Z listoŭ Leapolda Rodzieviča da Uładzimira Zyłki'. $B L L$, 149-56.

SKRYHAN, JANKA

234. Smołkin, M. 'Kruhi żyćcia. Litaraturny partret Janki Skryhana'. $P, 11$, 186-201.

STRALCOÜ, MICHAS

235. Samiakina, T. 'Dałučeńnie da śviatła'. $M, 11,173-9$.

SAMIAKIN, IVAN

236. Pasiaŭcova, M. 'Dźvie kancepcyi žyćcia ŭ ramanie I. Samiakina Sniežnyja zimy'. BLL, 116-26.

TANK, MAKSIM

237. Biernštajn, E. 'Paezija M. Tanka i sučasnaja biełaruskaja muzyka'. BLL, 78-87. 
VASILEVIC, ALENA

238. Siamionava, A. 'Imiem dabraty. Apaviadańni Aleny Vasileviě'. P, 12, 211-22. VIALUHIN, ANATOL

239. Majsiejčyk, A. 'Tvorčaść Anatola Vialuhina 40-ch hadoŭ'. BLL, 68-78.

VICBIC, JURKA

240. Bahrovič, A. 'Adyjšoŭ majstra mastackaha narysu'. Bi, 214, 1.

241. Dzie-ka, A. 'Jurka Vićbič'. Božym šlacham (London), 1-2, 2-8 \& 25-26.

ZYEKA, UEADZIMIR

242. Kipiel, J. 'Apošnija dni Uładzimiera Žyłki'. Bi, 218, 4.

243. Stankievič, S. 'Uładzimier Žyłka. Na 75-ja ŭhodki jahonaha naradžeńnia'. $B i, 218,2$.

\section{Religion}

244. Picarda, G. "The Heavenly Fire: A Study of the Origins of the Byelorussian New Testament and Psalms (1931)'. Božym šlacham (London), 1-2, 9-24.

245. Zaprudnik, J. 'Z historyi biełaruskaha pierakładu Jevanhiella'. Bi, 222, 6.

\section{Art. Architecture}

246. Anikin, V., Linevič, Ja. 'Gradostroitel'stvo Belorussii na sovremennom etape'. $S A B, 1,6-10$.

247. Canturia, V. 'Architekturnoje nasledije Belorussii'. $S A B, 1,47-8$.

248. Kałnin, V., Trepiet, L. 'Mirski zamak,. PHKB, 1, 26-32.

249. Kornejčik, V. 'Novyje goroda Belorussii'. $S A B, 4,11-20$.

250. Ladygina, O. 'Architektura oblastnych gorodov Belorussii'. SAB, 1, 16-20.

251. Lysenko, A. 'Respublika novych gorodov'. $S A B, 2,3-12$.

252. Łarčanka, M. 'Hraviury F. Skaryny'. B, 8, 28-9.

253. Malyšev, V., Kudrjavcev, D. 'Ziliščnoje stroitel'stvo v BSSR'. SAB, 1, 11-15.

254. Smataŭ, V. 'Hraviravana ŭ Hłusku'. $P H K B, 1,43-7$. (The 17th century Byelorussian engraver A. Tarasievič.)

255. Zasłaŭski, J. 'Architektura: siońnia i zaŭtra'. $P, 1,178-93$.

\section{Music. Theatre. Cinema}

256. Hajduk, M. 'Začaravannaja muzykaj'. BK, 53-69. (The composer Ludmiła Pańko.)

257. Harobčanka, T. 'Teatralnaja krytyčnaja dumka ŭ Biełarusi da Kastryčnika'. VAN, 2, 128-33.

258. Maślenikava, V. 'Muzyčnaja adukacyja ŭ Biełarusi 20-ch hadoŭ'. VAN, $4,102-9$.

259. Naumenko, Ja. 'Iz istorii belorussko-pol'skich kul'turnych svjazej pervoj poloviny XIX v. (S. Monjuško i Belorussija)'. VI, 144-9.

260. Reźniak, I. 'Tak naradžałasia Biełdziaržkino'. P, 1, 237-40.

261. Stankievič, S. '50 hod biełaruskaha kinamastactva'. $B i, 213,3-4$; 214, 2-3; 216, 2-4.

262. Vierasaŭ, D. 'Rozdum pra muzyku. Z nahody zbornika E. Zubovič "Kraj moj vasilkovy"'. $Z, 82-6$.

\section{Press. Radio. Television}

263. Apelinskaja, A. 'Dorevoljucionnyje belorusskije publicisty o žurnalistike'. $V B D U-I V, 2,64-9$.

264. Biahun, H. 'Vydavieckaja dziejnaść $\mathrm{KPB}(\mathrm{b})$ na pačatku Vialikaj Ajčynnaj vajny'. VBDU-IV, 3, 72-7.

265. Bondareva, E. 'Publicist v dokumental'nom kino'. VBDU-IV, 3, 77-83.

266. Ċarnuševič, A. 'Pytańni prapahandy dakumientalnaha i navukova-papularnaha kino'. VAN, 1, 98-107.

267. Gorčakova, I. 'Voprosy partijno-političeskogo prosveščenija kommunistov v žurnale Vpered (maj 1922 - janvar' 1925 g.)'. VBDU-IV, 1, 63-8.

268. Gordyševa, T. 'O nekotorych osobennostjach publicističeskogo osvjaščenija statističeskogo materiala $\mathrm{V}$ mestnoj pečati (1965-1970 gg.)'. VBDU-IV, 1, 69-73. 
269. Kucenka, V. 'Televizijnaje žyćcio dyłohii I. Mieleža'. VBDU-IV, 2, 69-71.

270. Safonova, V. 'Rola druku, kino i radyjo ŭ palityčnaj aśviecie sielskaha nasielnictva Biełarusi ǔ 1926-1932 hh.'. VAN, 2, 60-9.

\section{Addenda: Literature}

Biełaruskaja litaratura i litaraturaznaūstva. Minsk, 'BDU'. Vyp. 3, 1975.

271. Bakijevič, R. 'Dramaturhija K. Krapivy davajennaha casu'. 62-71.

272. Hrynčyk, M. 'Niekatoryja asablivaści žanravaha raźvićcia biełaruskaj litaratury XIX - pačatku XX stahodździa'. 34-44.

273. Jarac, V. 'Ab niekatorych rytmičnych asablivaściach liryki Pietrusia Broŭki'. 125-40.

274. Karabanava, L. 'La vytokaŭ dramaturhii Uł. Hałubka'. 117-24.

275. Lašuk, V. 'Krajaznaŭčaja rabota $\breve{u}$ škołach Biełarusi paślavajennych hadoŭ'. 81-91.

276. Lebiedzieŭ, U. 'Nazirańni nad stylem K. Cornaha - navielista'. 45-52.

277. Łaškievič, V. 'Prablemy adukacyi i vychavańnia ǔ tvorčaści biełaruskich piśmieńnikaŭ XIX - pačatku XX stahodździa'. 71-81.

278. Majsiejčyk, A. 'Paetyčny rozdum sučaśnika'. 27-34. (The poetry of Anatol Vialuhin.)

279. Malaŭka, M. 'Hiștoryja zahraničnaha pašparta B. I. Dunina-Marcinkieviča'. 141-5.

280. Miščančuk, M. 'Narodžana časam'. 3-15.

281. Praškovič, L. 'Ab žanrava-stylistyčnych asablivaściach ramana U. Karatkievißa Chrystos pryziamliǔsia ŭ Harodni'. 107-17.

282. Siemianovič, A. 'Biełaruskaja narodna-hieraičnaja drama druhoj pałaviny 30-ch hadoŭ'. 91-107.

283. Smaljanava, L. 'Biełaruskaja paema casu Vialikaj Ajčynnaj vajny'. 52-62.

284. Smykoŭskaja, V. 'Pafas sacyjalistyčnaha humanizmu'. 15-27. (The prose of Ivan Mielež.)

\section{A. Nadson}

Francis Skaryna Byelorussian Library, London 